\title{
Sex differences in COVID-19 mortality: opportunity to develop HSP27 (HSPB1) immunotherapy to treat hyper-inflammation?
}

\author{
Edward R. O'Brien ${ }^{1}$ (D) - Jagdeep K. Sandhu ${ }^{2}$ \\ Received: 20 July 2020 / Revised: 20 July 2020 / Accepted: 28 July 2020 / Published online: 6 August 2020 \\ (C) Cell Stress Society International 2020
}

\section{COVID-19, hyper-inflammation, and sex-specific features}

Since January 10, 2020, when the first death linked to the severe acute respiratory syndrome-related coronavirus 2 (SARS-CoV-2) occurred in Wuhan, China, more than 530,000 people have died (as of July 4, 2020). Globally, there are 11.2 million people infected with the virus, with 2.9 million in the USA alone and other populous countries surging. While there is a charge to develop a vaccine, as well as means of eliminating the virus from those infected (e.g., remdesivir), neither of these therapeutic strategies will directly address the major life-threatening complications that may occur once infected, namely, the profound upregulation of the innate immune system. Like the severe acute respiratory syndrome coronavirus that emerged in 2002 (SARS-1, caused by SARS$\mathrm{CoV}$ ) and the Middle East respiratory syndrome-related coronavirus of 2012 (MERS-CoV), COVID-19 (the disease associated with SARS-CoV-2) is associated with a storm of proinflammatory cytokines like IL- $1 \beta$, IL-6, and TNF. Precisely why some patients evolve to this hyper-inflammation state while others do not remains unclear but is likely due to nonviral factors that are specific to the host, including age and comorbidities (Yang et al. 2020). These cytokines play an important role in various tissue complications with acute respiratory distress syndrome (ARDS), a form of acute lung injury that is

Edward R. O'Brien

ermobrie@ucalgary.ca

1 Division of Cardiology, Department of Cardiac Sciences, University of Calgary Cumming School of Medicine, Libin Cardiovascular Institute, HRIC GC68, 3280 Hospital Drive NW, Calgary, AB T2N 4Z6, Canada

2 Human Health Therapeutics Research Centre, National Research Council Canada, Ottawa, ON, Canada without tangible therapeutic options apart from supportive care, of principal concern (Nieto-Torres et al. 2015).

What do we know about sex differences in the COVID-19? The COVID-19 mortality rate in men is double than that of females (Wu and McGoogan 2020). This is not surprising, as clinical and experimental studies with SARS-1 and MERS noted that the infection occurred more readily and was more persistent in males (Channappanavar et al. 2017; Karlberg et al. 2004; Mobaraki and Ahmadzadeh 2019; Zheng et al. 2020). Of note, there are exceptions to the male sex predominance in COVID-19 mortality rate. For example, in Canada, $54 \%$ of deaths are in females - however, this appears to be linked to factors other than sex, as $85 \%$ of the national deaths occurred in long-term care (LTC) facilities where the vast majority of residents are older females (Estabrooks et al. 2020). For the rest of the world, LTC residences do not represent the hot-bed of COVID-19 deaths (e.g., only $29 \%$ of deaths in Australia occurred in LTC). Hence, the global statistics overwhelmingly point to a male predominance of this disease, which has spurred a number of excellent opinions papers (Bischof et al. 2020; Suba 2020). Moreover, based on the assumption that ovarian hormones may be protective, a small clinical trial has begun in men $>18$ years and women $>55$ years with confirmed or suspected COVID-19, randomizing subjects to a transdermal patch containing estradiol or placebo (Estrogen Patch for COVID-19 Symptoms n.d.). With this in mind, we now postulate that heat shock protein 27 (HSP27), recently recognized to have potent antiinflammatory effects (Inia and O'Brien 2020), may also have a role in the treatment of COVID-19.

\section{Heat shock protein 27, an estrogen-responsive protein for treating COVID-19?}

HSP27 is a member of the small heat shock protein family that is primarily known as an intracellular chaperone and more 
recently for its extracellular, anti-inflammatory roles (Batulan et al. 2016). While looking for estrogen receptor-beta associated proteins that might be involved in modulating hormonal transcription, we discovered HSP27 and began to study the role of this protein in atherosclerosis. Investigations by several laboratories, including our own, highlight that HSP27 arterial expression and blood levels are higher in healthy subjects compared with patients with cardiovascular disease (Lepedda et al. 2009; Liang et al. 2016; Martin-Ventura et al. 2004; Miller et al. 2005; Park et al. 2006). What we also uncovered is a complex relationship between HSP27 and estrogens, as HSP27 acts as a repressor of estrogen-mediated transcription in vitro, yet its expression and extracellular release are also partially regulated by estrogens (e.g., there is an estrogen response element found in the HSP27 promoter) (Miller et al. 2005; Rayner et al. 2009). As well, we recently noted that natural IgG auto-antibodies to HSP27 (AAbs) are detectable in human blood (Chen et al. 2020b) and demonstrated how HSP27 immune complexes (ICs) form, dock at the cell membrane where they engage with Toll-like receptor 4 (TLR4), and compete with LPS to reduce inflammatory signaling (Shi et al. 2020). Interestingly, HSP27 activates the NF- $\mathrm{kB}$ pathway — but only modestly — resulting in the expression of both pro- and anti-inflammatory cytokines and proteins (Salari et al. 2013). Boosting HSP27 antibodies via vaccination reduces atherosclerosis and promotes the antiinflammatory effects of the HSP27 immune complex (Shi et al. 2020). It is the combination of the protein and its antibody that produces the therapeutic benefit - a concept that we refer to as HSP27 Immune $\underline{\text { Complex }} \underline{\text { Altered }} \underline{\text { Signaling and }}$ Transport (or ICAST; transport refers to cellular internalization of HSP27).

\section{HSP27 and COVID-19-related endothelial dysfunction}

Clinical evidence of endothelial dysfunction in COVID-19 patients is striking, ranging from vascular thrombosis and altered microvascular function (toes, fingers) to large artery strokes in relatively young individuals (Teuwen et al. 2020). Indeed, the presence of frank thrombosis in the lungs and to a lesser extent the microvessels of the heart are turning out to be the hallmarks of this clinical entity. With the pulmonary air space already compromised due to the development of ARDS, no amount of supplemental oxygen therapy (e.g., with ventilators) can overcome the effects of pulmonary circulatory obstruction that further impairs gas exchange. What can be done to improve the endothelium, and why are (pre-menopausal) women enjoying relative protection from COVID-19? Currently, there is no answer for that question; regardless, the acuity and magnitude of COVID-19 pandemic have prompted a "think now - do now" attitude to exploring a variety of therapeutic options. Indeed, Perdrizet and Hightower recently proposed that treatments with stannous chloride and hyperbaric oxygen (HBOT) may offer protection to the vascular endothelium that could reduce COVID-19 damage and invoke HSP70 as a biomarker for the cytoprotected state (Perdrizet and Hightower 2020). In contrast, we now propose that vaccination with HSP27 (or alternatively passive immunization with anti-HSP27 antibodies) may be worth exploring for the treatment of the inflammatory complications of COVID-19-including the important vascular effects (Table 1).

\section{NLRP3 inflammasome activation and COVID-19}

Elevated plasma levels of pro-inflammatory cytokines such as IL-1 $\beta$, IL-6, and TNF seem to drive SARS-CoV-2 pathogenicity in COVID-19 patients and is associated with adverse outcomes and poor prognosis (Huang et al. 2020). Blood levels of lactate dehydrogenase (LDH) levels are also highly elevated in patients with severe COVID-19 (Chen et al. 2020a). LDH is a cytosolic enzyme released from cells undergoing pyroptosis, an inflammatory form of cell death, possibly triggered by the activation of the NLRP3 inflammasome. The NLRP3 inflammasome is an innate immune sensor that is under tight regulation and requires two signals for full activation (Broz and Dixit 2016). The first signal is received from the binding of the virus to toll-like receptors on host cells leading to the NF-kB-mediated transcription of pro-IL-18 and pro-IL-1 $\beta$. The secondary signals are received in the form

Table 1 Potential therapeutic benefit of HSP27 immunotherapy for managing the inflammatory complications of COVID-19

$\begin{array}{ll}\text { Beneficial effects } & \begin{array}{l}\text { Implications for COVID-19 } \\ \text { pathophysiology }\end{array}\end{array}$

Estrogens augment synthesis and extracellular secretion (Rayner et al. 2009; Shi et al. 2019; Sun et al. 2011)

Competing for TLR4 and directing NF- $\mathrm{KB}$ activation towards anti-inflammatory mediators (Rayner et al. 2008; Shi et al. 2020)

Upregulating GM-CSF (Pulakazhi Venu et al. 2017; Salari et al. 2013)

Promoting endothelial repair and regrowth by upregulated VEGF (Ma et al. 2014)

Higher levels of HSP27 that may
attenuate inflammation
Reduced IL-1 $\beta$ and increased
IL-10
GM-CSF maintains alveolar
epithelial and macrophage
health-useful for treating
COVID-19 ARDS
Critical for prevention of
COVID-19 vascular complica-
tions like pulmonary emboli and
stroke

Higher levels of HSP27 that may 
of endogenous or exogenous ATP, reactive oxygen species, or lysosomal proteases released from damaged or dying cells leading to NLRP3 inflammasome assembly, activation of caspase-1, and subsequent secretion of IL-18 and IL-1 $\beta$, a mediator of fever, lung inflamamtion, and fibrosis (Shrivastava et al. 2016). Under normal physiological conditions, NLRP3-triggered responses lead to the death of infected cells, critical in limiting viral spread. However, over-activation of the NLRP3 inflammasome causes the hyper-inflammatory responses seen in COVID-19 patients, resulting in a vicious cycle of release of pro-inflammatory cytokines, pyroptosis, and infiltration of the lungs with inflammatory cells leading to ARDS, multi-organ failure and even death (De Nardo et al. 2014; Grailer et al. 2014). The elderly, who are already suffering from age-related low-grade inflammation (Franceschi et al. 2000) and a decline in their immune systems, are particularly susceptible due to their inability to mount type I and type III interferon responses to clear the viral infection (Molony et al. 2017). Hence a dysfunctional NLRP3 inflammasome and the impaired ability to clear viral infections are a perfect storm for COVID-19.

SARS-CoV encodes ion-channel viroporins, namely, protein E, ORF3a, and ORF8a, which are known to induce NLRP3 inflammasome activity and IL-1 $\beta$ production by altering intracellular ionic concentrations (Chen et al. 2019; Siu et al. 2019). Similarly, treatment of macrophages derived from COVID-19 patients with SARS-CoV-2 spike protein and nigericin activated the NLRP-3 inflammasome, resulting in IL-1 $\beta$ production (S.J. Theobald et al. 2020). Incubation of these cultures with MCC950, a small-molecule NLRP3 inhibitor, blocks IL-1 $\beta$ secretion and therefore highlights the potential value of antiinflammatory therapeutics for managing hyper-inflammation in COVID-19 patients. Accordingly, a number of clinical trials are ongoing, testing the potential therapeutic effect of individually or simultaneously blocking IL-6 and IL-1 cytokines using tocilizumab, canakinumab, siltuximab, and anakinra in patients with severe COVID-19. In a phase 3 clinical study, anakinra reduced mortality and the need for supplemental oxygen therapy (mechanical ventilation) in critically ill patients with COVID-19, thereby pointing to the need for further controlled studies (Huet et al. 2020). While these antibodies block the release of pro-inflammatory cytokines IL-6 and IL-1, they do not affect the secretion of other cytokines such as IL-18 and TNF; hence, they may be unsuccessful in breaking the vicious cycle of inflammation and tissue damage. Other synergistic or more broadly acting strategies may be needed.

\section{HSP27 and NLRP3 inflammasome activation}

Growing evidence suggests that HSPs play an important role in regulating the NLRP3 inflammasome activation. Although many HSPs act as alarmins and promote inflammation,
HSP27 and HSP70 have been shown to inhibit activation, supporting their role as modulators of inflammation (Batulan et al. 2016; Martine and Rebe 2019). Treatment of macrophages with exogenous recombinant HSP27 reduces the uptake of modified low-density lipoprotein (LDL), lowers IL-1 $\beta$ levels, and increases levels of an anti-inflammatory cytokine, IL-10 (Miller-Graziano et al. 2008; Rayner et al. 2008). Additionally, extracellular recombinant HSP27 inhibits modified LDL uptake by competing for scavenger receptors, SR-A and CD36 (Shi et al. 2020). Scavenger receptors bind modified LDL and intiate both signals 1 and 2 for complete NLRP3 inflammasome activation. Thus, the competition between HSP27 and scavenger receptors might down-regulate inflammation by preventing lysosomal disruption and subequent inflammasome activation (Duewell et al. 2010; Sheedy et al. 2013). Similarly, in a rat model of skeletal muscle disuse atrophy, prophylactic application of HSP27 attenuated NF-KB activation and skeletal muscle disuse atrophy (Dodd et al. 2009), possibly by inhibiting the priming step of inflammasome activation. These studies support the concept that extracellular HSP27 (or perhaps HSP27 ICAST) competes for the receptors that recognize the danger signals and targets pathways upstream of NF- $\mathrm{KB}$ and the inflammasome to dampen the cytokine storm and prevent the tissue damage characteristic of critically ill COVID-19 patients. Further study of the anti-inflammatory potential of HSP27 immuno-therapeutics for COVID-19 and other inflammatory disease states is ongoing, with a plan of moving from the bench to the clinic soon.

\section{References}

Batulan Z, Pulakazhi Venu VK, Li Y, Koumbadinga G, Alvarez-Olmedo DG, Shi C, O'Brien ER (2016) Extracellular release and signaling by heat shock protein 27: role in modifying vascular inflammation. Front Immunol 7:285. https://doi.org/10.3389/fimmu.2016.00285

Bischof E, Wolfe J, Klein SL (2020) Clinical trials for COVID-19 should include sex as a variable. J Clin Invest 130:3350-3352. https://doi. org/10.1172/JCI139306

Broz P, Dixit VM (2016) Inflammasomes: mechanism of assembly, regulation and signalling. Nat Rev Immunol 16:407-420. https://doi. org/10.1038/nri.2016.58

Channappanavar R, Fett C, Mack M, Ten Eyck PP, Meyerholz DK, Perlman S (2017) Sex-based differences in susceptibility to severe acute respiratory syndrome coronavirus infection. J Immunol (Baltimore, Md : 1950) 198:4046-4053. https://doi.org/10.4049/ jimmunol.1601896

Chen IY, Moriyama M, Chang MF, Ichinohe T (2019) Severe acute respiratory syndrome coronavirus viroporin $3 \mathrm{a}$ activates the NLRP3 inflammasome. Front Microbiol 10:50. https://doi.org/10. 3389/fmicb.2019.00050

Chen G et al (2020a) Clinical and immunological features of severe and moderate coronavirus disease 2019. J Clin Invest 130:2620-2629. https://doi.org/10.1172/JCI137244

Chen Y-X et al. (2020b) Heat shock protein 27 immune complex upregulates LDLR expression thereby reducing plasma cholesterol 
and atherogenesis bioRxiv:2020.2005.2021.102350 doi:https://oi. org/10.1101/2020.05.21.102350

De Nardo D, De Nardo CM, Latz E (2014) New insights into mechanisms controlling the NLRP3 inflammasome and its role in lung disease. Am J Pathol 184:42-54. https://doi.org/10.1016/j.ajpath.2013.09. 007

Dodd SL, Hain B, Senf SM, Judge AR (2009) Hsp27 inhibits IKKbetainduced NF-kappaB activity and skeletal muscle atrophy. FASEB J 23:3415-3423. https://doi.org/10.1096/fj.08-124602

Duewell P et al (2010) NLRP3 inflammasomes are required for atherogenesis and activated by cholesterol crystals. Nature 464:1357-1361

Estabrooks C, Flood CM, Straus S (2020) We must act now to prevent a second wave of long-term care deaths

Estrogen Patch for COVID-19 Symptoms (n.d.) https://ClinicalTrials. gov/show/NCT04359329

Franceschi C, Bonafè M, Valensin S (2000) Human immunosenescence: the prevailing of innate immunity, the failing of clonotypic immunity, and the filling of immunological space. Vaccine 18:17171720. https://doi.org/10.1016/S0264-410X(99)00513-7

Grailer JJ et al (2014) Critical role for the NLRP3 inflammasome during acute lung injury. J Immunol 192:5974-5983. https://doi.org/10. 4049/jimmunol.1400368

Huang C, Wang Y, Li X, Ren L, Zhao J, Hu Y, Zhang L, Fan G, Xu J, Gu X, Cheng Z, Yu T, Xia J, Wei Y, Wu W, Xie X, Yin W, Li H, Liu M, Xiao Y, Gao H, Guo L, Xie J, Wang G, Jiang R, Gao Z, Jin Q, Wang J, Cao B (2020) Clinical features of patients infected with 2019 novel coronavirus in Wuhan, China. Lancet 395:497-506. https://doi.org/10.1016/s0140-6736(20)30183-5

Huet $\mathrm{T}$ et al (2020) Anakinra for severe forms of COVID-19: a cohort study. Lancet Rheumatol 2:e393-e400. https://doi.org/10.1016/ S2665-9913(20)30164-8

Inia JA, O'Brien ER (2020) Role of heat shock protein 27 in modulating atherosclerotic inflammation. J Cardiovasc Transl Res. https://doi. org/10.1007/s12265-020-10000-Z

Karlberg J, Chong DSY, Lai WYY (2004) Do men have a higher case fatality rate of severe acute respiratory syndrome than women do? Am J Epidemiol 159:229-231. https://doi.org/10.1093/aje/kwh056

Lepedda AJ et al (2009) A proteomic approach to differentiate histologically classified stable and unstable plaques from human carotid arteries. Atherosclerosis 203:112-118. https://doi.org/10.1016/j. atherosclerosis.2008.07.001

Liang W, Ward LJ, Karlsson H, Ljunggren SA, Li W, Lindahl M, Yuan XM (2016) Distinctive proteomic profiles among different regions of human carotid plaques in men and women. Sci Rep 6:26231. https://doi.org/10.1038/srep26231

Ma X et al (2014) Heat shock protein 27 attenuates neointima formation and accelerates reendothelialization after arterial injury and stent implantation: importance of vascular endothelial growth factor upregulation. FASEB J 28:594-602. https://doi.org/10.1096/fj.13230417

Martine P, Rebe C (2019) Heat Shock Proteins and Inflammasomes. Int J Mol Sci:20. https://doi.org/10.3390/ijms20184508

Martin-Ventura JL, Duran MC, Blanco-Colio LM, Meilhac O, Leclercq A, Michel JB, Jensen ON, Hernandez-Merida S, Tunón J, Vivanco F, Egido J (2004) Identification by a differential proteomic approach of heat shock protein 27 as a potential marker of atherosclerosis. Circulation 110:2216-2219

Miller H, Poon S, Hibbert B, Rayner K, Chen YX, O'Brien ER (2005) Modulation of estrogen signaling by the novel interaction of heat shock protein 27 , a biomarker for atherosclerosis, and estrogen receptor beta. Arterioscler Thromb Vasc Biol 25:E10-E14. https://doi. org/10.1161/01.ATV.0000156536.89752.8e

Miller-Graziano CL, De A, Laudanski K, Herrmann T, Bandyopadhyay S (2008) HSP27: an anti-inflammatory and immunomodulatory stress protein acting to dampen immune function. Novartis Found Symp 291:196-208
Mobaraki K, Ahmadzadeh J (2019) Current epidemiological status of Middle East respiratory syndrome coronavirus in the world from 1.1.2017 to 17.1.2018: a cross-sectional study. BMC Infect Dis 19:351. https://doi.org/10.1186/s12879-019-3987-2

Molony RD, Nguyen JT, Kong Y, Montgomery RR, Shaw AC, Iwasaki A (2017) Aging impairs both primary and secondary RIG-I signaling for interferon induction in human monocytes. Sci Signal:10. https://doi.org/10.1126/scisignal.aan2392

Nieto-Torres JL et al (2015) Severe acute respiratory syndrome coronavirus $\mathrm{E}$ protein transports calcium ions and activates the NLRP3 inflammasome. Virology 485:330-339. https://doi.org/10.1016/j. virol.2015.08.010

Park HK et al (2006) Expression of heat shock protein 27 in human atherosclerotic plaques and increased plasma level of heat shock protein 27 in patients with acute coronary syndrome. Circulation 114:886-893

Perdrizet G, Hightower LE (2020) On barring the vascular gateway against severe COVID-19 disease. Cell Stress Chaperones. https:// doi.org/10.1007/s12192-020-01122-z

Pulakazhi Venu VK, Adijiang A, Seibert T, Chen YX, Shi C, Batulan Z, O'Brien ER (2017) Heat shock protein 27-derived atheroprotection involves reverse cholesterol transport that is dependent on GM-CSF to maintain ABCA1 and ABCG1 expression in ApoE(-/-) mice. FASEB J 31:2364-2379. https://doi.org/10.1096/fj.201601188R

Rayner K et al (2008) Extracellular release of the atheroprotective heat shock protein 27 is mediated by estrogen and competitively inhibits acLDL binding to scavenger receptor-a. Circ Res 103:133-141. https://doi.org/10.1161/circresaha.108.172155

Rayner K et al (2009) Heat shock protein 27 protects against atherogenesis via an estrogen-dependent mechanism: role of selective estrogen receptor beta modulation. Arterioscler Thromb Vasc Biol 29: 1751-1756. https://doi.org/10.1161/ATVBAHA.109.193656

S.J. Theobald AS, Kreer C, Zehner M, Fischer J, Albert M-C, Malin JJ, Gräb J, Winter S, de Silva US, Böll B, Köhler P, Gruell H, Suàrez I, Hallek M, Fätkenheuer G, Jung N, Cornely O, Lehmann C, Kashkar H, Klein F, Rybniker J (2020) The SARS-CoV-2 spike protein primes inflammasome-mediated interleukin-1- beta secretion in COVID-19 patient-derived macrophages. Res Square. https://doi. org/10.21203/rs.3.rs-30407/v1

Salari S et al (2013) Extracellular HSP27 acts as a signaling molecule to activate NF-kappaB in macrophages. Cell Stress Chaperones 18:5363. https://doi.org/10.1007/s12192-012-0356-0

Sheedy FJ et al (2013) CD36 coordinates NLRP3 inflammasome activation by facilitating intracellular nucleation of soluble ligands into particulate ligands in sterile inflammation. Nat Immunol 14:812820. https://doi.org/10.1038/ni.2639

Shi C, Ulke-Lemee A, Deng J, Batulan Z, O'Brien ER (2019) Characterization of heat shock protein 27 in extracellular vesicles: a potential anti-inflammatory therapy. FASEB J 33:1617-1630. https://doi.org/10.1096/fj.201800987R

Shi C, Deng J, Chiu MH, Chen Y-X, O'Brien ER (2020) Heat shock protein 27 immune complex altered signaling and transport (ICAST): novel mechanisms of attenuating inflammation bioRxiv: 2020.2005.2031.126581 doi:https://doi.org/10.1101/2020.05.31. 126581

Shrivastava G, Leon-Juarez M, Garcia-Cordero J, Meza-Sanchez DE, Cedillo-Barron L (2016) Inflammasomes and its importance in viral infections. Immunol Res 64:1101-1117. https://doi.org/10.1007/ s12026-016-8873-z

Siu KL et al (2019) Severe acute respiratory syndrome coronavirus ORF3a protein activates the NLRP3 inflammasome by promoting TRAF3-dependent ubiquitination of ASC. FASEB J 33:8865-8877. https://doi.org/10.1096/fj.201802418R

Suba Z (2020) Prevention and therapy of COVID-19 via exogenous estrogen treatment for both male and female patients. J Pharm Pharm Sci 23:75-85. https://doi.org/10.18433/jpps31069 
Sun J et al (2011) Attenuation of atherogenesis via the anti-inflammatory effects of the selective estrogen receptor beta modulator 8beta-VE2. J Cardiovasc Pharmacol 58:399-405

Teuwen L-A, Geldhof V, Pasut A, Carmeliet P (2020) COVID-19: the vasculature unleashed. Nat Rev Immunol. https://doi.org/10.1038/ s41577-020-0343-0

Wu Z, McGoogan JM (2020) Characteristics of and important lessons from the coronavirus disease 2019 (COVID-19) outbreak in China: summary of a report of 72314 cases from the Chinese Center for Disease Control and Prevention. JAMA 323:1239-1242. https://doi. org/10.1001/jama.2020.2648
Yang J et al (2020) Prevalence of comorbidities and its effects in patients infected with SARS-CoV-2: a systematic review and meta-analysis. Int J Infect Dis 94:91-95. https://doi.org/10.1016/j.ijid.2020.03.017

Zheng S et al (2020) Viral load dynamics and disease severity in patients infected with SARS-CoV-2 in Zhejiang province, China, Januarymarch 2020: retrospective cohort study. BMJ 369:m1443. https:// doi.org/10.1136/bmj.m1443

Publisher's note Springer Nature remains neutral with regard to jurisdictional claims in published maps and institutional affiliations. 